\title{
Investigation of Hydro-piercing Method for Stainless Steels by Finite Element Method
}

\author{
Habip Gökay KORKMAZ ${ }^{1,2}$, Serkan TOROS ${ }^{2,3}$, Mehmet HALKACI ${ }^{4}$ and Hüseyin Selçuk HALKACI ${ }^{1}$ \\ ${ }^{1}$ Department of Mechanical Engineering, Selcuk University, Konya, Turkey \\ 2 Department of Mechanical Engineering Nigde Omer Halisdemir University, Nigde, Turkey \\ ${ }^{3}$ Nigde Omer Halisdemir University Prof. Dr. T. Nejat Veziroglu Clean Energy Research Center, Nigde, Turkey \\ ${ }^{4}$ Technical Sciences Vocational School of Higher Education, Selcuk University, Konya, Turkey
}

\begin{abstract}
Researches and studies on hydroforming process, which is a method that is getting more and more popular every day thanks to its many advantages in application, are ongoing. It is possible to pierce- the holes on a tube or sheet hydroformed part using hydropiercing method after the forming operation. In this study, hydropiercing process of a 304 stainless steel is simulated via the LS-Dyna in 2D axial symmetry model. In the simulations two types of punch movement was investigated to determine the contribution to the burr formation. In the simulations, JonsonCook hardening and damage model were used to determine the initiation of the crack on the samples. As a result, the burr formation can be eliminated by the two step movement of the punch through the piercing operation.
\end{abstract}

\section{Introduction}

Hydroforming is a material forming process that uses pressurized fluid instead of traditional male and female mold systems. The hydroforming process has begun to be used extensively in recent years in geometries that are particularly difficult to form $[1,2]$. Although hydroforming systems first applied in the 1890 s, they could not be used for many years due to the difficulty of control. Especially in recent years, the method has become widely used with the development of computerized control systems, [3, 4]. Hydroforming process has advantages such as higher drawing ratio, better dimensional and surfaces quality, less springback etc., also in this system, process steps can be reduced considerably and the number of parts in multi-part systems can be reduced [5].

In the hydroforming process, piercing can be performed using pressurized fluid and punch instead of conventional die and punch. This method is called as hydropiercing. Hydropiercing method has many advantages such as low cost, dimensional accuracy and low burr formations [6-8]. Wu et al. [9] reported that, hydropiercing process is the best choice for piercing holes when it comes to mass production of hydroformed parts and curve axial parts.

In literature, some studies have been conducted to hydropiercing process. Wu et al. [9] modeled the tube hydropiercing process for different pressure values in six different (Constant equivalent plastic strain criterion (Strain Criterion), Cockcroft ve Latham [10], Brozzo [11, 12], Ayada [13], Generalized Plastic Work Per Unit Volume (Freudenthal) $[11,12]$ ve Rice ve Tracey [14]) ductile fracture criteria using Abaqus Finite Element Analysis (FEA). When they compared the experimental results with FEA results, they observed that the best similarity was obtained with the Rice and Tracey criterion analysis at $60 \mathrm{MPa}$ pressure. Hassannejadasl et al. [15] investigate tube hydropiercing process and the burrs formed after the piercing process on the part surface numerically and experimentally. Numerical studies were carried out to determine the burrs and component surface quality by using different damage criteria and the model performances were compared. In that study, the Johnson Cook (JC) damage criterion [16], constant equivalent plastic strain criterion, constant equivalent plastic strain criterion with cut-off stress triaxiality and the Gurson Tvergaard Needleman (GTN) criterion [17] were used. They observed that the results of JC, shear and constant equivalent plastic strain criterion with cut-off stress triaxiality are very close to the experimental study results. Liu et al. [18] $60 \mathrm{~mm}$ diameter, $2 \mathrm{~mm}$ thick tube-shaped AISI 1020 steel material pierced three different flange geometry punches with hydropiercing-flanging method. They have determined the effect of the geometry of the flange area on the punch to the hole quality. They supported their work with the numerical results they obtained. Numerical studies used Abaqus finite element code, as ductile fracture criterion, Race and Tracey criterion were used. Shiomi et al. [8] studied sheet hydropiercing process with different pressure values and hole diameters experimentally and numerically. In the study, three different types of piercing with different amounts of movement of the punch were evaluated for the neck area and the burrs formation. They determined that the punch 
push-recede method is the best method in terms of the minimum burr formation. However, there is a limited number of studies [8] on sheet hydropiercing.

\section{Modelling of hydropiercing process}

\subsection{Johnson-cook hardening model}

One of the most commonly used material hardening model in finite element simulations of the stamping processes or cutting operation is the Johnson-Cook hardening model which depends on the both temperature and strain rate. The definition of the stress with respect to the plastic strain, temperature and strain rate is given in Equation (1). In the given equation $A, B, C$ and $m$ are the material parameters, which are determined by fitting the equation to the experimental stress strain data that are obtained under different temperature and strain rates. In addition, $T^{*}$ is the homolog temperature that is given in Equation (2).

$$
\begin{gathered}
\bar{\sigma}=\left(A+B\left(\overline{\bar{\varepsilon}}^{\mathrm{pl}}\right)^{n}\right)\left[1+C \ln \left(\dot{\bar{\varepsilon}}^{\mathrm{pl}} / \dot{\bar{\varepsilon}}_{0}^{\mathrm{pl}}\right)\right]\left(1-T^{* m}\right) \\
T^{*}=\left(T-T_{\text {room }}\right) /\left(T_{\text {melt }}-T_{\text {room }}\right)
\end{gathered}
$$

\subsection{Johnson-cook damage criteria}

In this study, it is necessary to use a damage criteria in finite element simulation modelling of the hyrdropiercing method to determine the initiation of the crack and burr formation. In the literature, the Johnson-Cook (JC) damage criterion is frequently used for modelling of the cutting and/or crack problems in machining and high velocity crash simulations. This criterion is given in Equation (3).

$\bar{\varepsilon}_{\mathrm{f}}^{\mathrm{pl}}=\left[D_{1}+D_{2} \exp \left(-D_{3} \eta\right)\right]\left[1+D_{4} \ln \left(\dot{\bar{\varepsilon}}^{\mathrm{pl}} / \dot{\bar{\varepsilon}}_{0}\right)\right]\left(1+D_{5} T^{*}\right)$

In Equation (1), $\eta, \dot{\bar{\varepsilon}}^{\mathrm{pl}}$ and $T^{*}$ indicate triaxiality, deformation rate and homologous temperature values respectively, and $D_{1}-D_{5}$ values shows material constants. $\bar{\varepsilon}_{\mathrm{f}}^{\mathrm{pl}}$ indicates the amount of elongation at break of the samples tensile test. The triaxiality can be calculated by the ratio of the mean stresses to equivalent stress value. In the study, the variation of the triaxiality with the given deformation can be calculated by Equation (4).

$$
\sigma_{x}=\bar{\sigma} \ln \left[1+\frac{a}{2 R}\left(1-\frac{y^{2}}{a^{2}}\right)\right]
$$

In Equation (4), $\sigma_{x}$ represents the tensile component measured in the pull direction and $\bar{\sigma}$ represent efective streess. Furthermore, $\mathrm{R}$ and $\mathrm{y}$ values indicate the notch radius and the depth of notch depth varying with deformation. Although the triaxiality vary with the given deformation for the specimens, in the study initial triaxiality $(\eta)$ values of the samples are given in Table 1 .

\section{Finite element hydropiercing process}

In the current study, finite element simulation of the hydropiercing process was carried for the 2D axi-symmetric condition as depicted in Figure 1. as can be seen from the figure three die system component was used in the simulations. One of the component in the design is the blank holder force, which is numbered as 1 , is used to hold the materials through punch movement and $600 \mathrm{kN}$ blank holder force was applied on the material. Two kinds of punch movement was applied through the simulations. In first case, the punch were moved to down during the pressurizing of the system and in the second case, the punch were moved to upward about the sheet thickness and then was moved too downward about three times of the sheet thickness. In the simulations, $100 \mathrm{MPa}$ pressure was applied to the selected region of the sheets as depicted in Figure 1. The sheet was meshed with different element density to visualize the burr formation and reduce the computation time. As can be seen from the figure, the piercing region is meshed very fine and the $0.01 \mathrm{~mm}$ for the radial direction and $0.007 \mathrm{~mm}$ for the normal direction were chosen for this region. The other regions were meshed with the triangular element form to reduce the total amount of the elements. The element formulation (ELFORM) was selected as 15 which is used for the axi-symmetric modelling of the system. The contact definition is one of the important parameter to avoid the penetration between the tools and the sheet blank, and AUTOMATIC SURFACE TO SURFACE was selected in the simulations.

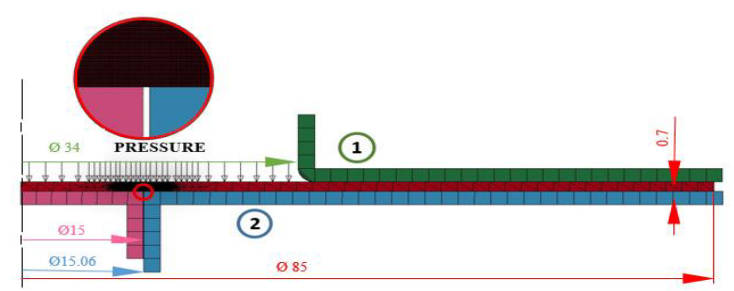

Figure 1.Finite Element Modeling of Hydropiercing Process

\section{Experimental procedure for JC hardening and damage model}

In Figure $2(\mathrm{a}, \mathrm{b})$, the special tensile test samples for determining the Johnson-Cook hardening and damage model parameters, are illustrated. The simple tensile test samples were prepared according to the ASTM E8 standard and the other notched samples were chosen according to reference [19] to obtain the different amount of triaxiality on the samples and to determine the effects on the stress-strain diagram. The samples were prepared by water jet cutting system. The all tests were carried out at Shimadzu Autograph $100 \mathrm{kN}$ tensile test devise with a non-contact deformation measurement system.

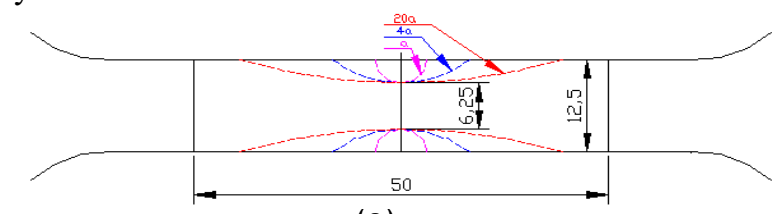

(a) 


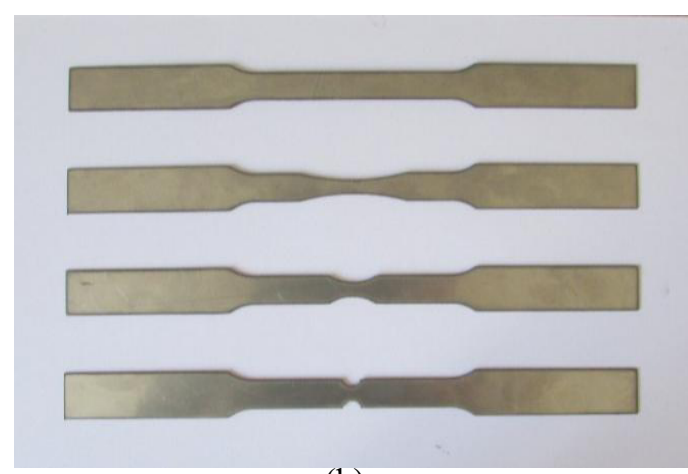

(b)

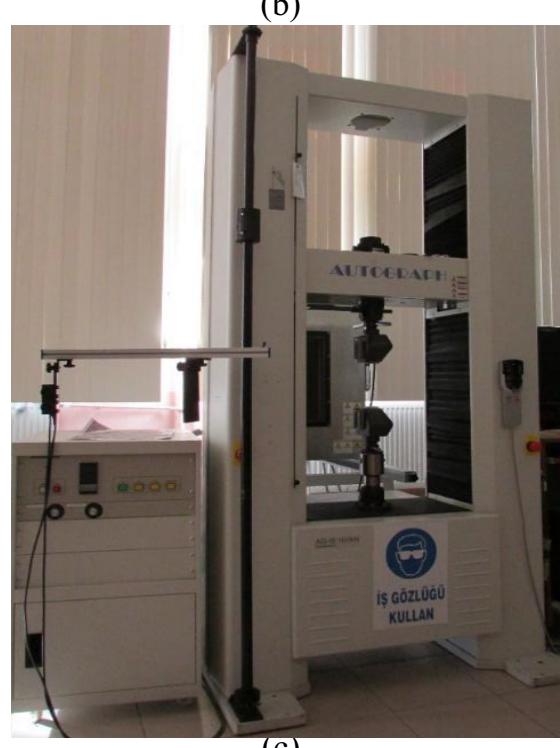

(c)

Figure 2. (a) Schematic tensile test specimens, (b) Tensile test specimens, (c) Tensile test setup

\section{Results and discussion}

In the first step of the study, the initial triaxiality values of the samples were tabulated in Table 1. As can be seen from the table, the triaxiality which affect the formability of the samples decrease with increasing the notch radius. The simple tensile test samples have a triaxiality value of 0.33 , the narrowest $(a), 0.74$ triaxiality value.

Table 1. The calculated triaxiality values

\begin{tabular}{|c|c|c|}
\hline Notch & R & Triaxiality \\
\hline $20 \mathrm{a}$ & 62,5 & 0,36 \\
\hline $4 \mathrm{a}$ & 12,5 & 0,45 \\
\hline $\mathrm{a}$ & 3,125 & 0,74 \\
\hline
\end{tabular}

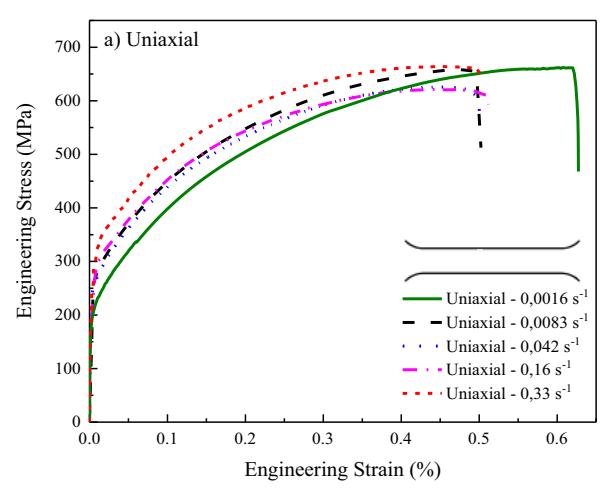

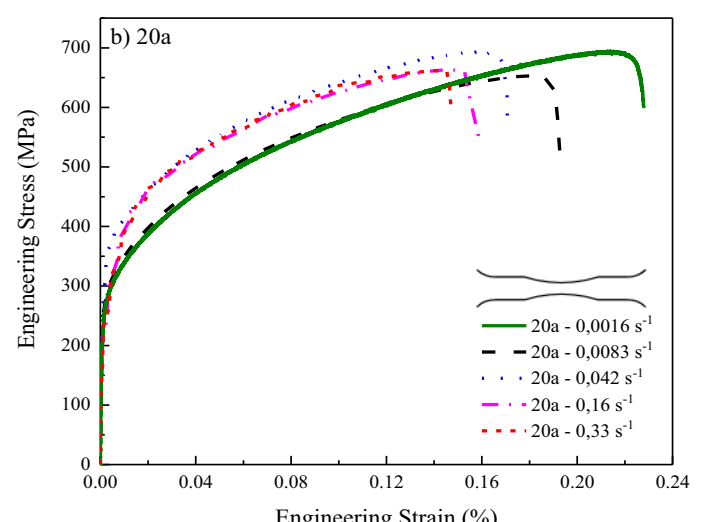
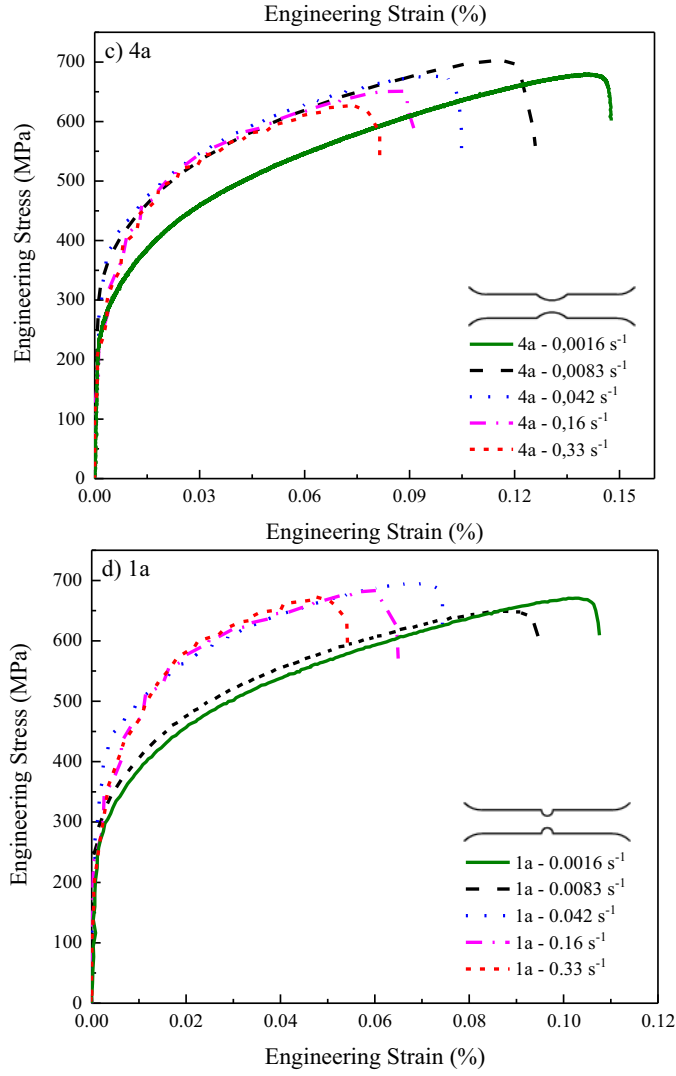

Figure 3. Average engineering stress-strain response of uniaxial and notched tensile specimens (a) Uniaxial, (b) 20a, (c) $4 \mathrm{a}$, (d) $1 \mathrm{a}$

In Figure 3 (a-d), the tensile test results of the 304 stainless steel sheets have different amount of notch radius were depicted in the engineering form. The strain values were calculated for a constant $12.5 \mathrm{~mm}$ gauge length. The tests were carried out at different strain rates varied from $0.0016-0.33 \mathrm{~s}^{-1}$. As can be seen from the figures, the rate sensitivity of the material can be obviously seen from the differences of the stress values at different strain rates. Besides the strain rate, the stress values of the samples increase with decreasing the notch radius. The variation of the yield strength with initial triaxiality values were depicted in Figure 4 (a). Although it has fluctuation at different triaxiality values, the general trend has the increased form. In addition, the variation of the yield strength with respect to the strain rate is also depicted in the same figure. Similar to triaxiality effect, the yield strength increase with the 
strain rate. In the study, the failure strains were also determined via the Equation 3. In the equation, the initial and final cross sectional areas are used. The final cross sections of the specimens were measured via the caliper and the results were given in Figure 4 (b). s can be seen from the figure the strain values at fracture point for both triaxiality and strain rate decrease.

$$
\varepsilon_{f}=\ln \left(\frac{A_{0}}{A_{f}}\right)
$$
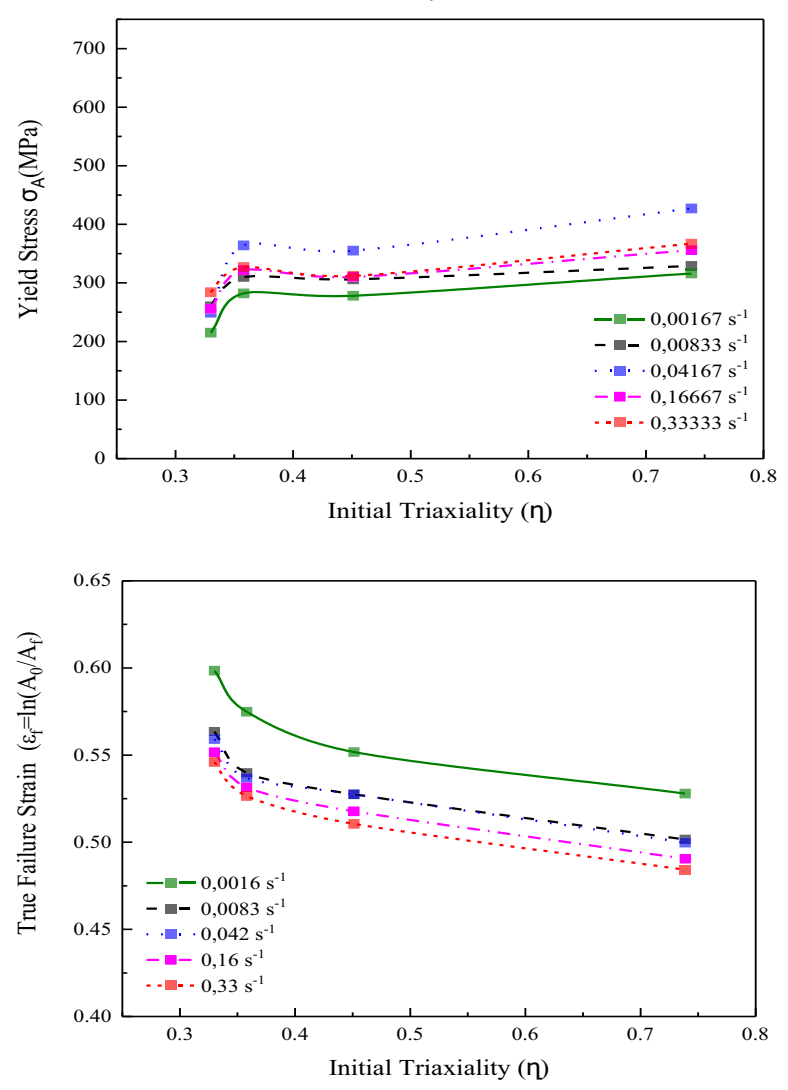

Figure 4. Variation of yield stress for different triaxiality and strain rates

The experimental results are then used to determine the JC hardening and damage model parameters. First of all the JC hardening model was fitted to experimental stress strain data obtained for different strain rates. The fitting performance of the model was plotted in Figure 5 (a) with experimental one. As can be seen from the figure, although there are some over estimated points, the general performance is acceptable for a finite element simulation. Besides the hardening model, the JC damage model's performance was also evaluated. The fitting results were depicted in Figure 5 (b) and model parameters were tabulated in Table 2.

Table 2. JC hardening and damage model parameters

\begin{tabular}{|c|c|c|c|c|}
\hline A (Mpa) & B (Mpa) & $\mathrm{n}$ & $\mathrm{C}$ & $\mathrm{m}$ \\
\hline 205.578 & 1637.984 & 0.811 & 0.014 & 1 \\
\hline D1 & D2 & D3 & D4 & D5 \\
\hline 0.53 & 0.5 & -6.8 & -0.014 & 0 \\
\hline
\end{tabular}

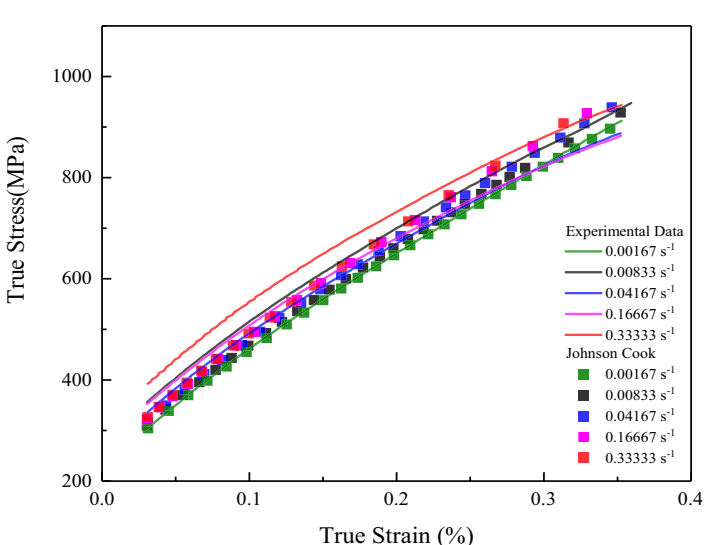

(a)

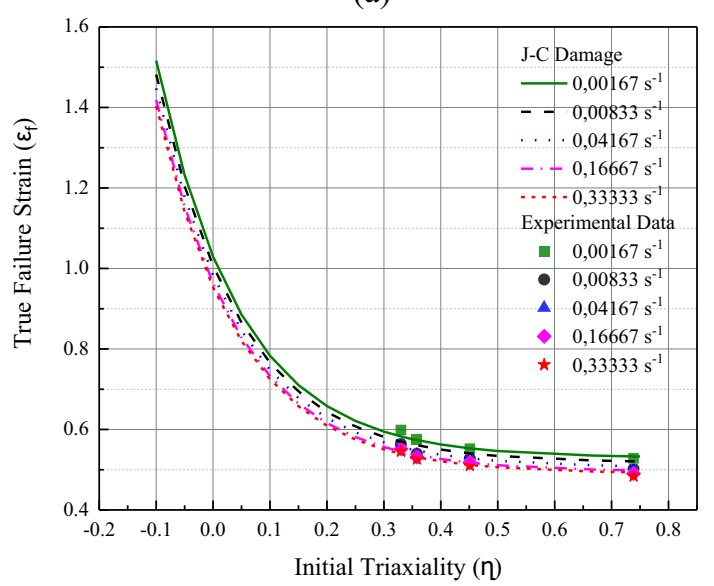

(b)

Figure 5. Johnson-Cook hardening and damage model curves fitted to experimental data

As aforementioned before, the finite element simulation of the hydropiercing method was analyzed for a 304 stainless steel has $0.7 \mathrm{~mm}$ thick in 2D axial symmetric condition. In the simulations, two different piercing method which was related with punch movement, was carried out to determine the performance on eliminating of the burr formation. In the first case, the punch is pulled directly down (Punch recede method), while in the second case the punch is moved up and then pulled down to obtain additional hardening on the material (Punch push-recede method). The simulation results were given in Figure 6 for both cases step by step to compare the piercing stages. As can be seen from the figure, a small indention was occurred on the sheet when the punch move upwards. This can be assumed as the initiation of the crack on the sheet cutting line. However, this situation is not valid for the first case of the simulation.

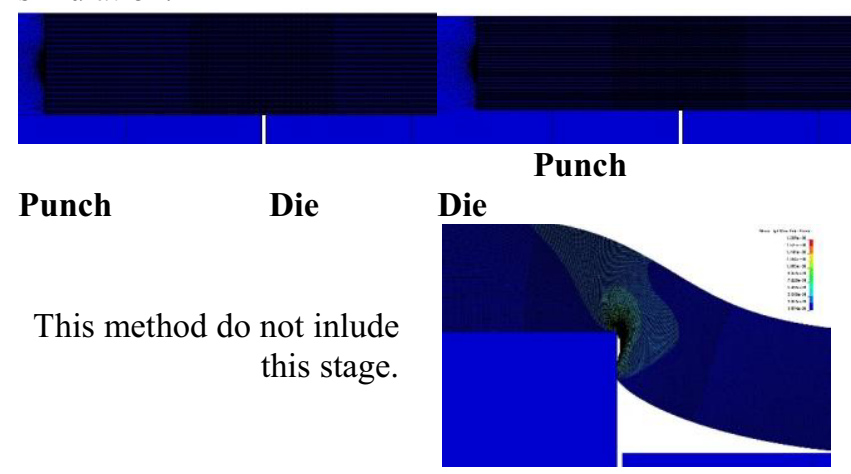




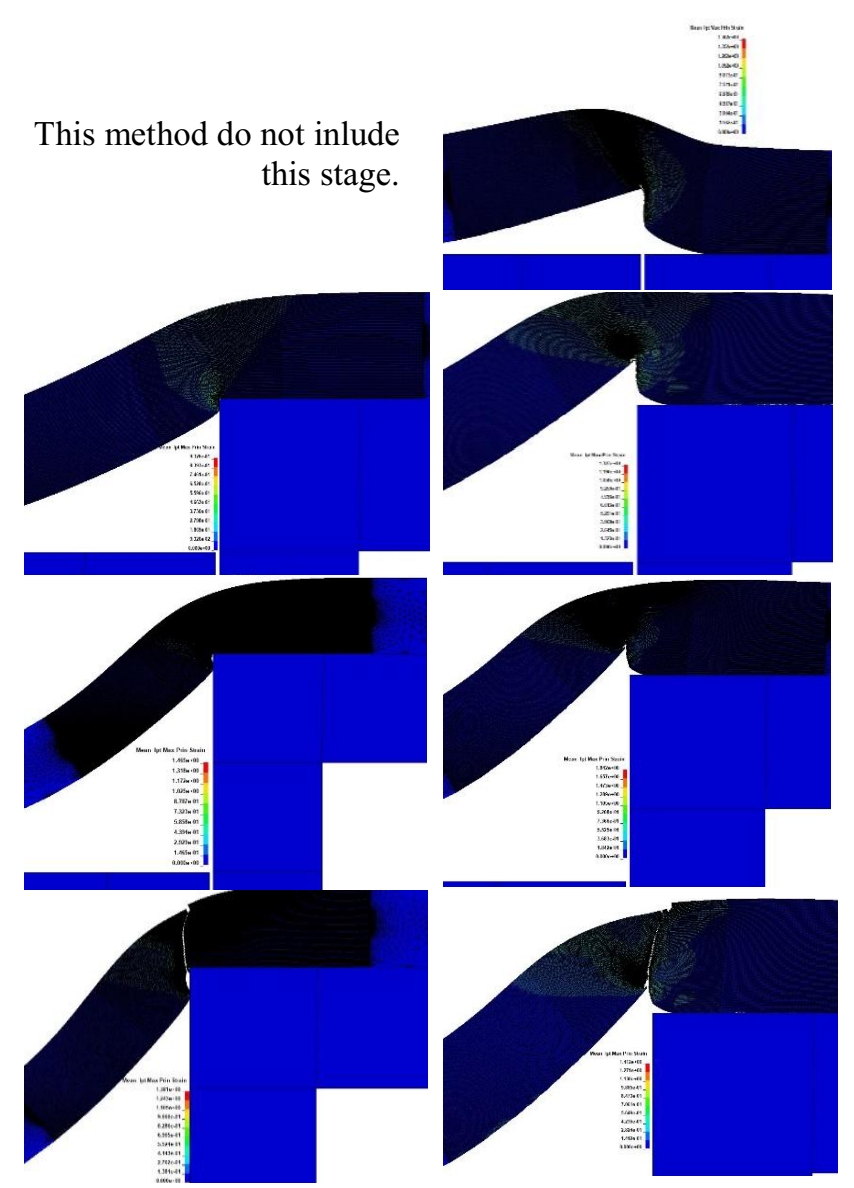

(a)

(b)

Figure 6. Hydropiercing stages (a) Punch recede method, (b) Punch push-recede method

Although the material was pierced at the end of the punch movement that defined in simulation, the surface quality is not same for the both cases. This situation was illustrated in Figure 7. As depicted in the focused figures, the burr formation can be obviously seen in the first case called punch recede method while there is no bur formation in the second case called punch pushrecede method.

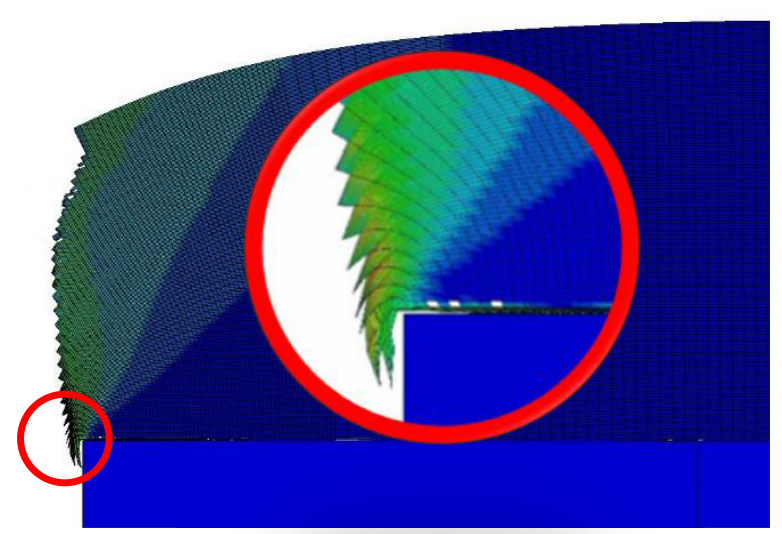

(a)

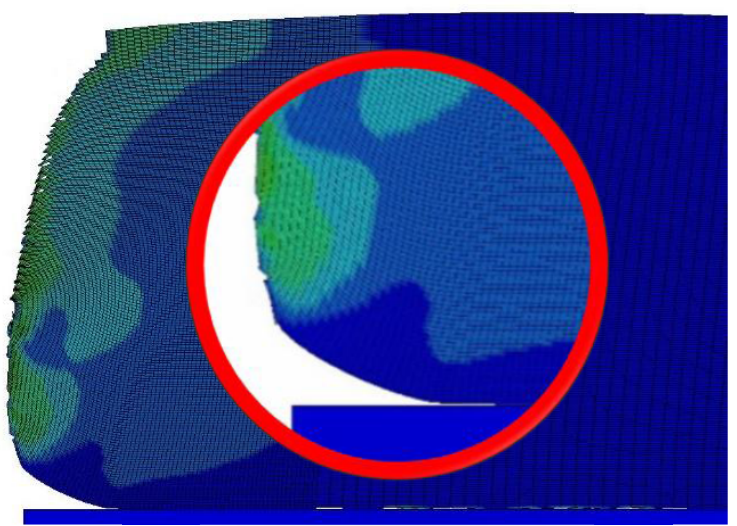

(b)

Figure 7. Burr formation (a) Punch recede method (b)Punch push-recede method

\section{Conclusion}

In this study, the performance of hydro-piercing method is evaluated in the view of the surface quality of the final products. One of the important problem in such a stamping processes, the burr formation is the key issue since it limits a healthy installation. When we compared the applied two methods in the view of the surface quality of the sheets, it is clearly seen that the punch push-recede method is the best choice for the burr formation free is eliminated.

\section{References}

1. A. Kocanda, H. Sadlowska, Automotive component development by means of hydroforming: a review, Arch Civ Mech Eng 8, (3) 55-72 (2008).

2. S.M. Kulkarni, V.V. Ruiwale, M.S. Jadhao, A.A. Kadam, S.R. Kale, A review on Hydroforming Processes, International Journal of Current Engineering and Technology 160-163 (2017).

3. L.H. Lang, Z.R. Wang, D.C. Kang, S.J. Yuan, S.H. Zhang, J. Danckert, K.B. Nielsen, Hydroforming highlights: sheet hydroforming and tube hydroforming, J Mater Process Tech 151, (1-3) 165 177 (2004).

4. Q. Wang, Hydromechanical deep-drawing, New Technol. New Process. 5, 23-34 (1994).

5. S.H. Zhang, Z.R. Wang, Y. Xu, Z.T. Wang, L.X. Zhou, Recent developments in sheet hydroforming technology, J Mater Process Tech 151, (1-3) 237241 (2004).

6. S.S. Kim, C.S. Han, Y.S. Lee, Development of a new burr-free hydro-mechanical punching, J Mater Process Tech 162, 524-529 (2005).

7. M. Uchida, M. Kojima, Hydropiercing of Tube Wall in Hydroforming, International conference; 7th, Technology of plasticity, Advanced Technology of Plasticity, Yokohama, Japan, 2002, pp. 1483-1488.

8. M. Shiomi, Y. Ueda, K. Osakada, Piercing of steel sheet by using hydrostatic pressure, Cirp Ann-Manuf Techn 55, (1) 255-258 (2006). 
9. Z.G. Wu, S.H. Li, W.G. Zhang, W.R. Wang, Ductile fracture simulation of hydropiercing process based on various criteria in 3D modeling, Mater Design 31, (8) 3661-3671 (2010).

10. C.M. G., L.D. J., Ductility and the Workability of Metals, Journal of the Institute of Metals 96, 33-39 (1968).

11. S.E. Clift, P. Hartley, C.E.N. Sturgess, G.W. Rowe, Fracture Prediction in Plastic-Deformation Processes, Int J Mech Sci 32, (1) 1-17 (1990).

12. H. P, P. I, S. C., Numerical Modelling of Material Deformation Processes Research, Development and Applications, Springer, Berlin, 1992.

13. R. Hambli, M. Reszka, Fracture criteria identification using an inverse technique method and blanking experiment, Int J Mech Sci 44, (7) 13491361 (2002).

14. R. J.R., T. D.M., On the ductile enlargement of voids in triaxial stress fields, Journal of the
Mechanics and Physics of Solids 17, (3) 201-217 (1969).

15. A. Hassannejadasl, D.E. Green, W.J. Altenhof, C. Maris, M. Mason, Numerical modeling of multistage tube hydropiercing, Mater Design 46, 235-246 (2013).

16. G.H. Majzoobi, F.R. Dehgolan, Determination of the constants of damage models, Procedia Engineer 10, (2011).

17. M. Feucht, D.-Z. Sun, T. Enhart, T. Frank, Recent development and applications of the Gurson model, LS-DYNA Anwenderforum D II, 21-32 (2006).

18. W. Liu, J. Hao, G. Liu, G.L. Gao, S.J. Yuan, Influence of punch shape on geometrical profile and quality of hole piercing-flanging under high pressure, Int J Adv Manuf Tech 86, (5-8) 1253-1262 (2016).

19. D. Anderson, S. Winkler, A. Bardelcik, M.J. Worswick, Influence of stress triaxiality and strain rate on the failure behavior of a dual-phase DP780 steel, Mater Design 60, 198-207 (2014). 